\title{
Heat and Mass Transfer in Membrane Distillation used for Desalination with Slip Flow
}

\author{
Jamel Orfi ${ }^{1}$, Nizar Loussif ${ }^{2,3 *}$ andPhilip A. Davies ${ }^{4}$ \\ ${ }^{1}$ Department of Mechanical Engineering, College of Engineering, King Saud University, PO Box 800, \\ Riyadh, 11421, Saudi Arabia; E-Mail: orfij@ksu.edu.sa \\ ${ }^{2}$ Unité de Recherche Matériaux, Energie et Energies Renouvelables, Faculté des Sciences Gafsa, \\ Université de Gafsa, Gafsa, Tunisie. \\ ${ }^{3}$ École Nationale d'Ingénieur de Monastir, Université de Monastir, Monastir, Tunisie \\ ${ }^{4}$ Sustainable Environment Research Group, School of Engineering and Applied Science, Aston \\ University, Birmingham, B4 7ET, UK; E-Mail: p.a.davies@aston.ac.uk
}

*Author to whom correspondence should be addressed; loussif_nizare@yahoo.fr

\begin{abstract}
A theoretical model for the transport phenomena in an air gap membrane distillation is presented. The model is based on the conservation equations for the mass, momentum, energy and species within the feed water solution as well as on the mass and energy balances on the membrane sides. Slip flow occurs due to the hydrophobic properties of the membrane. The slip boundary condition applied on the feed saline solution-membrane interface is taken into consideration showing its effects on process parameters particularly permeate flow, heat transfer coefficient and thermal efficiency. The theoretical model was validated with available experimental data and was found to be in good agreement especially when the slip condition is introduced. Increasing slip length from zero to $200 \mu \mathrm{m}$ was found to increase the permeate flux and the thermal efficiency by $33 \%$ and $1.7 \%$ respectively.
\end{abstract}

Keywords: desalination; membrane distillation; modeling; simulation; slip flow

\section{Nomenclature}

$\begin{array}{ll}\mathrm{C} & \text { Mass fraction of } \mathrm{NaCl} \\ \mathrm{C}_{\mathrm{in}} & \text { Mass fraction of } \mathrm{NaCl} \text { at the entrance } \\ \mathrm{C}_{\mathrm{p}} & \text { Specific heat }[\mathrm{kJ} / \mathrm{kg} \mathrm{K}] \\ \mathrm{c}_{\mathrm{s}} & \text { Mole fraction of } \mathrm{NaCl} \\ \mathrm{D}_{\mathrm{s}} & \text { Diffusion coefficient of } \mathrm{NaCl}\left[\mathrm{m}^{2} / \mathrm{s}\right] \\ \mathrm{D}_{\mathrm{v} / \mathrm{a}} & \text { Coefficient of vapor-air mass diffusion }\left[\mathrm{m}^{2} / \mathrm{s}\right] \\ \mathrm{g} & \text { Acceleration of gravity }\left[\mathrm{m} / \mathrm{s}^{2}\right] \\ \mathrm{h}_{\mathrm{fg}} & \text { Latent heat of evaporation }[\mathrm{kJ} / \mathrm{kg}]\end{array}$


$\mathrm{h}_{\mathrm{x}} \quad$ Local convective heat transfer coefficient $\left[\mathrm{W} / \mathrm{m}^{2} \mathrm{~K}\right]$ Length-averaged permeate flux $\left[\mathrm{kg} / \mathrm{m}^{2} \mathrm{~h}\right]$

$\mathrm{J}_{\mathrm{V}}$ Local permeate flux $\left[\mathrm{kg} / \mathrm{m}^{2} \mathrm{~s}\right]$

$\mathrm{K}$ Permeability of the membrane

Thermal conductivity $[\mathrm{kW} / \mathrm{mK}]$

$\mathrm{L}$ Membrane length [m]

Half-width of the flow channel [m]

$\mathrm{M}_{\mathrm{v}}$ Molar mass of water vapor $[\mathrm{kg} / \mathrm{kmol}]$

$\mathrm{N}_{\mathrm{X}}$ Number of nodes along $\mathrm{x}$ direction

$\mathrm{N}_{\mathrm{y}}$ Number of nodes along y direction pressure $[\mathrm{Pa}]$

$\operatorname{Pr}$ Prandtl number

QC Conductive heat flux $\left[\mathrm{kJ} / \mathrm{m}^{2} \mathrm{~h}\right]$

QL Latent heat flux $\left[\mathrm{kJ} / \mathrm{m}^{2} \mathrm{~h}\right]$

$\mathrm{Q}_{\mathrm{T}} \quad$ Total heat flux $\left[\mathrm{kJ} / \mathrm{m}^{2} \mathrm{~h}\right]$

$\mathrm{Re} \quad$ Reynolds number

$\mathrm{R}_{\mathrm{g}}$

Thermal resistance of the air gap

$\mathrm{R}_{\mathrm{f}}$

Thermal resistance of the condensate film

$\mathrm{R}_{\mathrm{m}}$

Thermal resistance of the membrane

$\mathrm{R}_{\mathrm{p}}$ Thermal resistance of the cooling plate

$\mathrm{Ru}$ Universal gas constant $[\mathrm{kJ} / \mathrm{kmol} / \mathrm{K}]$

Sc

Schmidt number

$\mathrm{T}$

Temperature $\left[{ }^{\circ} \mathrm{C}\right]$

$\mathrm{U}_{\text {in }} \quad$ Inlet velocity $[\mathrm{m} / \mathrm{s}]$

$\mathrm{U}$

Velocity component in $\mathrm{x}$ direction $[\mathrm{m} / \mathrm{s}]$

$\mathrm{V}$

Velocity component in y direction $[\mathrm{m} / \mathrm{s}$ ]

$\mathrm{X}$

Coordinate along to the solution flow [m]

coordinate normal to the solution flow [m]

$\mu$

Dynamic viscosity $\left[\mathrm{kgm}^{-1} \mathrm{~s}^{-1}\right]$

$\rho$

Density $\left[\mathrm{kgm}^{-3}\right]$

$\varepsilon$

Porosity

$\delta$

Thickness or width [m]

$\chi$

Tortuosity

$\eta$

Process thermal efficiency

\section{Subscripts}




$\begin{array}{ll}\text { c } & \text { cooling plate } \\ \mathrm{f} & \text { condensate film } \\ \mathrm{g} & \text { air gap } \\ \text { in } & \text { inlet } \\ \mathrm{m} & \text { membrane } \\ \mathrm{mm} & \text { membrane material } \\ \mathrm{moy} & \text { average } \\ \mathrm{s} & \text { saline water } \\ \mathrm{T} & \text { total } \\ \mathrm{v} & \text { vapor }\end{array}$

AGMD Air gap membrane distillation

DCMD Direct contact membrane distillation

MD Membrane distillation

SWMD Sweeping gas membrane distillation

VMD Vacuum membrane distillation 


\section{Introduction}

Membrane distillation (MD) has been widely investigated the last two decades as a novel and promising technique for desalination. The driving force in MD process is the difference in vapor pressure of water caused by an existing temperature difference across the membrane. Thus, vapor molecules are transported from the high vapor pressure (high temperature) side to the low vapor pressure (low temperature) side of the membrane. This trans-membrane vapor pressure difference may be maintained with one of four possibilities applied on the permeate side leading to four different configurations namely Direct Contact Membrane Distillation (DCMD), Air Gap Membrane Distillation (AGMD), Vacuum Membrane Distillation (VMD) and Sweeping Gas Membrane Distillation (SWMD) [1,2]. One of the key parameters affecting the process performance is related to the membrane properties.

For the MD process, the membrane supports the liquid-gas interface on which the evaporation takes place. This can be achieved by using hydrophobic surfaces characterized by alternating patches of either a liquid-solid interface or a gas-liquid interface [2,3]. One can have therefore alternating boundary conditions at the membrane surfaces of either no slip at the solid-liquid interface or no shear at the gasliquid interface. Modeling the microscopic behavior of the flow over hydrophobic surfaces is not an easy task. However, it is possible as proposed by Ramon et al. [4] to model the macroscopic behavior by introducing an effective slip parameter accounting for the deviations of the flow from the no-slip basic case.

The phenomenon of slip can occur for both gases and liquids. However, there is a fundamental difference between the slip in gas micro-flows and the slip in liquid flows. Slip in liquids is encountered as a consequence of the interaction between a coated surface and the adjacent liquid particle. Thus, liquid slip can occur even when the continuum hypothesis is valid [5].

For a hydrophilic surface, Garimella and Sobhan [6] studied the transport in micro-channels and concluded that analyses based on Navier-Stokes and energy equations can adequately predict the flow and heat transfer characteristics in micro-channels having a hydraulic diameter greater than $50 \mu \mathrm{m}$. In the case of hydrophilic surface, experimental studies have confirmed the validity of the no-slip boundary condition down to few nano-meters [7]; despite, the occurrence of slip in hydrophilic surface has also been studied and confirmed [8]. When a surface is coated with hydrophobic material, the fluid molecules adjacent to the surface do not stick to the solid boundary resulting in an overall velocity slip. This slip velocity is related to the normal velocity gradient of the fluid adjacent to the wall with a slip length $b$ which can be described as the imaginary distance within the solid where the velocity extrapolates to zero. Slip velocity can be presented in the following form [4]:

$\left.U\right|_{y=0}=\left.b \frac{\partial U}{\partial y}\right|_{y=0}$

Tretheway and Meinhart [9,10] experimentally showed an apparent fluid slip in micro-channels with hydrophobic walls. The micron-resolution particle image velocimetry ( $\mu$-PIV) was applied to measure velocity profiles of flow through 30x300 mm channels. They measured an apparent slip velocity at the wall for water flowing through a microchannel coated with hydrophobic octadecyltrichlorosilane. The slip velocity at the wall was approximately $10 \%$ of the free stream velocity which produces a slip length 
of about $1 \mu \mathrm{m}$. Pit et al. [11] provided experimental evidence of liquid slip at the wall for hexadecane flowing between two rotating parallel disks kept at a distance of $190 \mu \mathrm{m}$. They measured a slip length of $0.4 \mu \mathrm{m}$ when the surface was coated with octadecyltrichlorosilane (OTS). Cottin-Bizzone et al. [12] studied experimentally water flow across hydrophilic and hydrophobic surfaces; they found slip lengths of approximately $b=0.02 \mu \mathrm{m}$.

On the other hand, a superhydrophobic surface can dramatically reduce the hydrodynamic resistance and a slip length higher than $185 \mu \mathrm{m}$ has been reported by Choi and Kim [13, 14]. They obtained the slip length through torque measurement with a commercial rheometer. A cone and plate arrangement, the most popular geometry because of the uniform shear rate over a sample, was used. For the bottom plate, the prepared test membrane is placed over a rheometer stage with temperature set by a Peltier plate. The test liquids are dispensed between the cone and the test membrane. When a cone of radius $r$ and very small cone angle $\Theta_{0}$ rotates at angular velocity $\Omega$, the governing equation of the Couette flow with a slip on the substrate using Navier's hypothesis about the wall slip and expanding the wall shear stress into a Taylor series, the torque $\mathrm{M}$ on the rotating cone can be calculated. Derived from the torque measurement, slip length can be calculated as [13]:

$b=\frac{r \theta_{0}}{4}\left(1-\sqrt{\frac{8 \theta_{0}}{\pi \Omega r^{3}} \frac{M}{\mu}-\frac{13}{3}}\right)$

$\mathrm{Ou}$ and Rothstein [15] were among the first to demonstrate experimentally that superhydrophobic surfaces could reduce drag in laminar flows. Slip lengths greater than $25 \mu \mathrm{m}$ were measured.

It's important to notice that many techniques are used to measure slip length. Some techniques are used to have direct measurements of slip length in flows past hydrophobic surfaces. Joseph and Tabeling [16] and Tretheway and Meinhart [10] utilize micro-particle image velocimetry ( $\mu$-PIV) measurements to determinate slip length. Pit et al. [17] used total internal reflection fluorescence microscopy (TIRF) to measure the fluorescence recovery after photobleaching and determine the slip velocity of hexadecane flowing past a lyophobically modified, smooth sapphire surface. Jin et al. [18] combined TIRF of submicrometer particles with particle tracking velocimetry (PTV) to measure the velocity of water near a glass surface coated with a self-assembled monolayer of OTS.

A number of studies have calculated slip lengths indirectly from pressure-drop Choi et al. [19], Schnell [20] or friction-factor measurements [12,21] of simple fluids flowing past non wetting smooth surfaces.

On the other side, it is also of importance to mention some techniques used to generate superhydrophobic surfaces such as plasma treatment, lithography, sol gel technology, nanoparticle deposition and fluoroalkylsilane coating [22,23].

In membrane distillation process, commercial hydrophobic polyvinylidene fluoride (PVDF) flat-sheet membrane HVHP, usually used in membrane distillation, is coated with a $\mathrm{TiO}_{2}$ solution by the low temperature hydrothermal process followed by fluorination through vacuum filtration with FTCS solution to create a superhydrophobic membrane. More explanation about this technique is detailed by Razmjou et al. [24].

The majority of previous studies on membranes for water treatment and desalination were performed within the continuum regime and the effect of slip flow at a membrane surface was studied only by very 
few authors. Singh and Laurence $[25,26]$ focused on the effect of slip velocity at the membrane surface of an ultra-filtration unit on the concentration polarization for tube flow and channel flow systems. Soundalgekar et al. [27] studied laminar slip flow through a uniform circular pipe with small suction, and significant impact of slip velocity on the hydrodynamic flow is shown. Recently, Ramon et al. [4] presented a two-dimensional, boundary layer model describing the heat transfer in the feed channel of a vacuum membrane distillation (VMD) module. The effect of slip velocity on the VMD performance in terms of permeate flux and thermal efficiency was found to be significant. The degree of temperature polarization is reduced and an increase in the evaporation mass flux is observed.

The purpose of this study is to present a two-dimensional model for the transport phenomena in the feed channel of an AGMD module. The slip velocity boundary condition is considered and discussed showing its effects on the desalination unit performance.

\section{Mathematical model}

The axisymmetric flow field is modeled using the two dimensional steady-state partial differential equations expressing conservation of mass (overall and species), energy and momentum using constant fluid properties. Viscous dissipation, thermal radiation and Soret and Dufour effects are neglected. The natural convection effects in the feed solution are supposed negligible. Besides, the convective effect in the air gap is also ignored. The condensation temperature $T_{c}$, is supposed to be uniform. The calculation domain is limited to the flow, heat and mass transfer in the hot saline water region.

\subsection{Process description}

The configuration considered in this study is AGMD. Hot saline water flows inside a channel. The wall of this channel consists of a micro porous hydrophobic (non wettable) membrane through which only water vapor can diffuse and the liquid water is retained. The vapor is condensed on the cold surface of the outer wall. The latter is impermeable and can be cooled by the feed sea water. An air gap is interposed between the membrane and the condensation surface separating the evaporator and the condenser. The temperature difference between the inner and the outer tubes creates a partial pressure gradient forcing the vapor to diffuse through the membrane and the air gap [28]. Fig. 1 shows a description of the physical model considered in the present study. The calculation domain is limited to the flow and heat and mass transfers in the hot saline water region. 


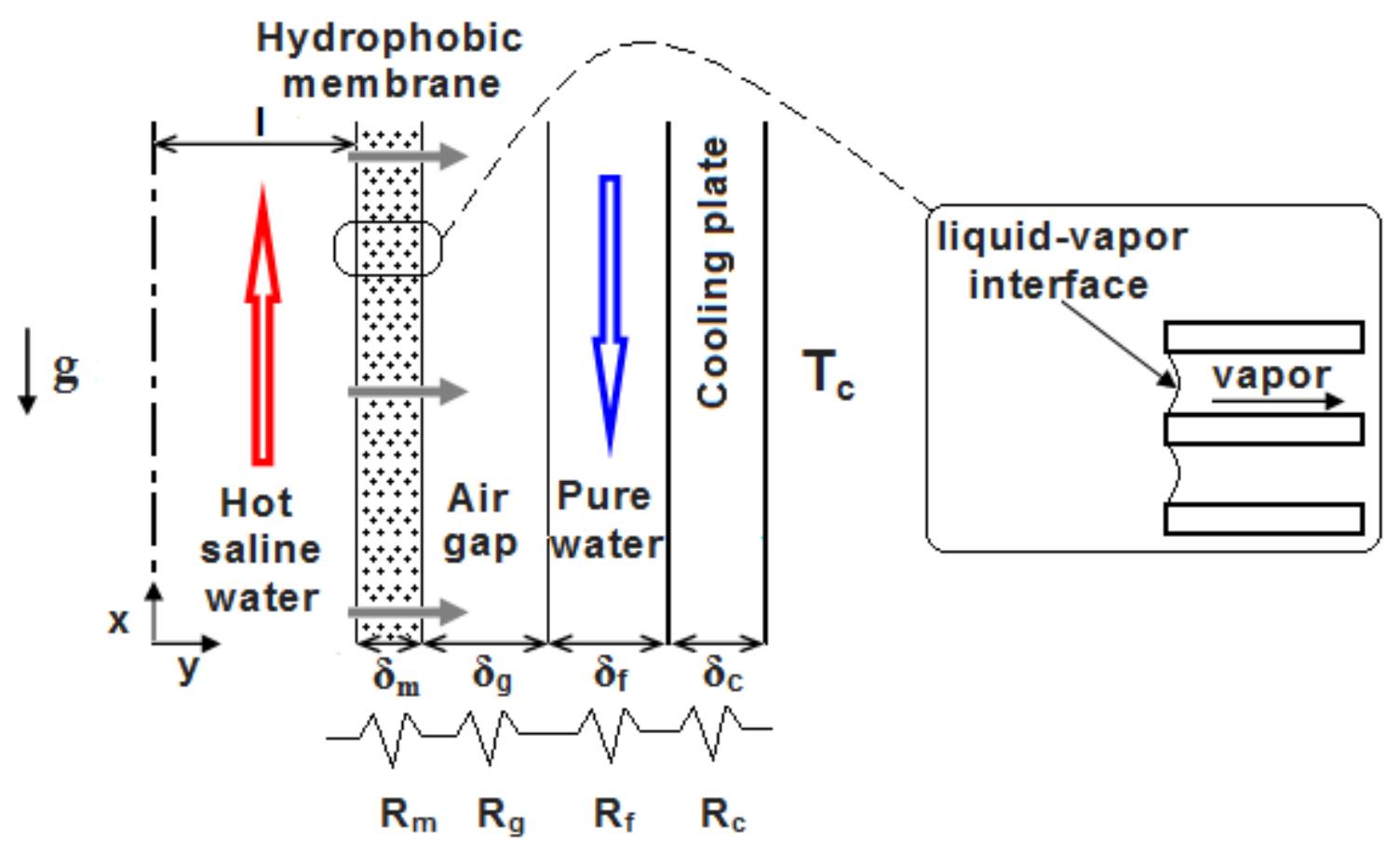

Figure 1: Schematic diagram of the AGMD unit

\subsection{Governing equations}

The partial differential equations governing the flow, heat and mass transfer within the hot feed water are those of conservation of mass, momentum in $\mathrm{x}$ and $\mathrm{y}$ directions, energy and species. These equations can be normalized using the following dimensionless variables:

$\bar{x}=\frac{x}{l}, \bar{y}=\frac{y}{l}, \bar{U}=\frac{U}{U_{\text {in }}}, \bar{V}=\frac{V}{U_{\text {in }}}, \bar{P}=\frac{P}{\rho U_{\text {in }}^{2}}, \bar{T}=\frac{T-T_{c}}{T_{i n}-T_{c}}, \bar{C}=\frac{C}{C_{i n}}$

Therefore, in non-dimensional form the governing equations are:

$\frac{\partial}{\partial \bar{x}}(\bar{U})+\frac{\partial}{\partial \bar{y}}(\bar{V})=0$

$\left(\bar{U} \frac{\partial \bar{U}}{\partial \bar{x}}+\bar{V} \frac{\partial \bar{U}}{\partial \bar{y}}\right)=-\frac{\partial \bar{P}}{\partial \bar{x}}+\frac{1}{\operatorname{Re}}\left[\frac{\partial^{2} \bar{U}}{\partial \overline{x^{2}}}+\frac{\partial^{2} \bar{U}}{\partial \overline{y^{2}}}\right]$

$\left(\overline{\mathrm{U}} \frac{\partial \overline{\mathrm{V}}}{\partial \overline{\mathrm{x}}}+\overline{\mathrm{V}} \frac{\partial \overline{\mathrm{V}}}{\partial \overline{\mathrm{y}}}\right)=-\frac{\partial \overline{\mathrm{P}}}{\partial \overline{\mathrm{y}}}+\frac{1}{\operatorname{Re}}\left[\frac{\partial^{2} \overline{\mathrm{V}}}{\partial \overline{\mathrm{x}^{2}}}+\frac{\partial^{2} \overline{\mathrm{V}}}{\partial \overline{\mathrm{y}^{2}}}\right]$

$\left(\overline{\mathrm{U}} \frac{\partial \overline{\mathrm{T}}}{\partial \overline{\mathrm{x}}}+\overline{\mathrm{V}} \frac{\partial \overline{\mathrm{T}}}{\partial \overline{\mathrm{y}}}\right)=\frac{1}{\operatorname{RePr}}\left[\frac{\partial^{2} \overline{\mathrm{T}}}{\partial \overline{\mathrm{x}^{2}}}+\frac{\partial^{2} \overline{\mathrm{T}}}{\partial \overline{\mathrm{y}^{2}}}\right]$

$\left(\overline{\mathrm{U}} \frac{\partial \overline{\mathrm{C}}}{\partial \overline{\mathrm{x}}}+\overline{\mathrm{V}} \frac{\partial \overline{\mathrm{C}}}{\partial \overline{\mathrm{y}}}\right)=\frac{1}{\operatorname{ReSc}}\left[\frac{\partial^{2} \overline{\mathrm{C}}}{\partial \overline{\mathrm{x}^{2}}}+\frac{\partial^{2} \overline{\mathrm{C}}}{\partial \overline{\mathrm{y}^{2}}}\right]$ 
The boundary conditions in dimensionless form are:

- Inlet of the saline solution $(\mathrm{x}=0)$

$\bar{U}=1, \bar{V}=0, \bar{T}=1, \bar{C}=1$

- Symmetry conditions $(\mathrm{y}=0)$

$\frac{\partial \bar{U}}{\partial \bar{y}}=0, \frac{\partial \bar{T}}{\partial \bar{y}}=0, \frac{\partial \bar{C}}{\partial \bar{y}}=0, \bar{V}=0$

- Outlet of the saline solution $(\mathrm{x}=\mathrm{L})$

$\frac{\partial \bar{U}}{\partial \bar{x}}=0, \frac{\partial \bar{V}}{\partial \bar{x}}=0, \frac{\partial \bar{T}}{\partial \bar{x}}=0, \frac{\partial \bar{C}}{\partial \bar{x}}=0$

- Feed saline solution - membrane interface

Liquid slip boundary condition, occurred in the feed saline solution-membrane interface, due to hydrophobic and superhydrophobic membrane characteristics, is expressed by equation (1) and could be written using the dimensionless variables as:

$\bar{U}=\frac{b}{l} \frac{\partial \bar{U}}{\partial \bar{y}}$

So, in equation (10a), $b=0$ refers to the non slip boundary condition.

For a steady-state liquid evaporation, continuity requires that $V=J_{v} / \rho_{s}[29]$, where $J_{v}$ is the local vapor flux and $\rho_{s}$ the density of the liquid (here the liquid is the saline solution), so we obtain in dimensionless form:

$\bar{V}=\frac{J_{v}}{U_{\text {in }} \rho_{s}}$

At the saline solution-membrane interface, the conduction within the saline solution will be the sum of heat required for the evaporation $\left(Q_{L}=J_{v} h_{f g}\right)$ and heat transferred by conduction across the membrane $\left(Q_{c}\right)$ : 
$-k_{s} \frac{\partial T}{\partial y}=Q_{c}+Q_{L}$

And in dimensionless form we obtain:

$$
\frac{\partial \bar{T}}{\partial \bar{y}}=\frac{l\left(Q_{c}+Q_{L}\right)}{k_{s}\left(T_{c}-T_{i n}\right)}
$$

Where $\mathrm{Q}_{\mathrm{c}}$ can be calculated as:

$$
Q_{c}=\frac{T_{s m}-T_{c}}{R_{m}+R_{g}+R_{f}+R_{c}}
$$

Where $T_{s m}$ is the temperature at the saline solution-membrane interface, $R_{m}, R_{g}, R_{f}$ and $R_{c}$ are respectively the thermal resistance of the membrane, the air gap, the condensate film and the cooling plate

$$
R_{m}=\frac{R_{m m} R_{v}}{R_{m m}+R_{v}}
$$

$R_{m m}$ and $R_{v}$ are respectively the thermal resistance of the membrane material and the vapor flow through the membrane and $R_{m m}=\delta_{m} / k_{m} ; R_{v}=1 / J_{v} C_{p}$

$k_{m}=\varepsilon k_{a}+(1-\varepsilon) k_{m m}$

$k_{m m}$, and $k_{a}$ are the thermal conductivity of the membrane material, and the air, respectively. $\delta_{m}$ and $\varepsilon$ are the membrane thickness and porosity respectively.

$$
R_{g}=\frac{R_{a} R_{v}}{R_{a}+R_{v}}
$$

Where $R_{a}=\delta_{g} / k_{a}, R f=\delta_{f} / k_{f}$ and $R_{c}=\delta_{c} / k_{c}$

For the species equation, the boundary condition is:

$D_{s} \frac{\partial C}{\partial y}=\frac{J_{v}}{\rho_{s}}$

And in dimensionless form we obtain:

$$
\frac{\partial \bar{C}}{\partial \bar{y}}=\frac{J_{v} l}{\rho_{s} D_{s} C_{i n}}
$$


The vapor flux generated by the membrane will condensate on the internal side of the cooling plate, and for a thin film, the condensate film thickness $\delta_{f}$ can be calculated as given by [30,31]:

$\delta_{f}(z)=\left(\frac{3 \mu_{f} \int_{0}^{z} J_{v}(z) d z}{g \rho_{f}\left(\rho_{f}-\rho_{v}\right)}\right)^{1 / 3}$

Where $\mathrm{z}=\mathrm{L}-\mathrm{x}$

Many authors have adopted empirical approaches to describe the mass transfer across the membrane.

Stephan's law is used to give the general mass flux form [31]:

$$
J_{v}=K \Delta P_{v}
$$

Where:

$J_{v}$ : local vapor flux generated across the membrane;

$K$ : Permeability of the membrane;

$\Delta P_{v}:$ Water vapor pressure difference between the membrane sides;

The vapor pressure $P_{v}$ can be calculated using the Antoine's equation:

$$
P_{v}=\exp \left(23.1964-\frac{3816.44}{T-46.13}\right)
$$

The membrane permeability $K$ is defined for the molecular diffusion as:

$$
K=\frac{\varepsilon D_{v / a} M_{v} P_{T}}{\chi \delta_{m} P_{a, m o y} R_{u} T_{m o y, m}}
$$

The effect of the presence of the salt in the solution on the vapor pressure at the hot surface of the membrane side has been accounted for by using Raoult's law [31]:

$$
P=\left(1-c_{s}\right) P_{v}
$$

where $c_{s}$ is the mole fraction of $\mathrm{NaCl}$.

The averaged permeate flux is obtained by integrating equation (13) over the membrane length $L$ :

$$
J=\frac{1}{L} \int_{0}^{L} J_{v}(x) d x
$$

The averaged conduction heat flux is defined as: 
$\overline{Q_{C}}=\frac{1}{L} \int_{0}^{L} Q_{C}(x) d x$

The averaged total latent heat flux is:

$\overline{Q_{L}}=\frac{1}{L} \int_{0}^{L} Q_{L}(x) d x$

The total heat transfer is:

$\overline{Q_{T}}=\frac{1}{L} \int_{0}^{L} Q_{T}(x) d x$

Therefore, the process thermal efficiency can be defined as:

$\eta=\frac{\bar{Q}_{L}}{\bar{Q}_{T}}$

\section{Numerical model and validation}

The control volume method and the Simpler algorithm [32] was used for the solution. A griddependence analysis of the method of solution was performed as mentioned in Table 1 . The values are practically independent of the chosen grid. We selected the grid size of 250,40 for the simulations conducted in this work. The computed results for AGMD using the present model were validated by comparing them with Izquierdo-Gil's AGMD experimental ones [33] considering properties for aqueous sucrose solutions. They were found to be in very good agreement as shown in Fig. 2. The numerical model was also verified in earlier studies [28].

Table 1: Influence of grid size on the permeate flux and thermal efficiency

\begin{tabular}{|l|c|c|c|c|}
\hline $\mathbf{N x}, \mathbf{N y}$ & $\mathbf{2 5 0 , 4 0}$ & $\mathbf{3 5 0 , 4 0}$ & $\mathbf{2 5 0 , 5 0}$ & $\mathbf{3 5 0 , 5 0}$ \\
\hline $\mathbf{J}\left[\mathrm{kg} / \mathrm{m}^{2} \mathrm{~h}\right]$ & 5.7216 & 5.7203 & 5.7214 & 5.72039 \\
\hline $\boldsymbol{\eta}$ & 0.91802 & 0.91804 & 0.91805 & 0.91804 \\
\hline
\end{tabular}




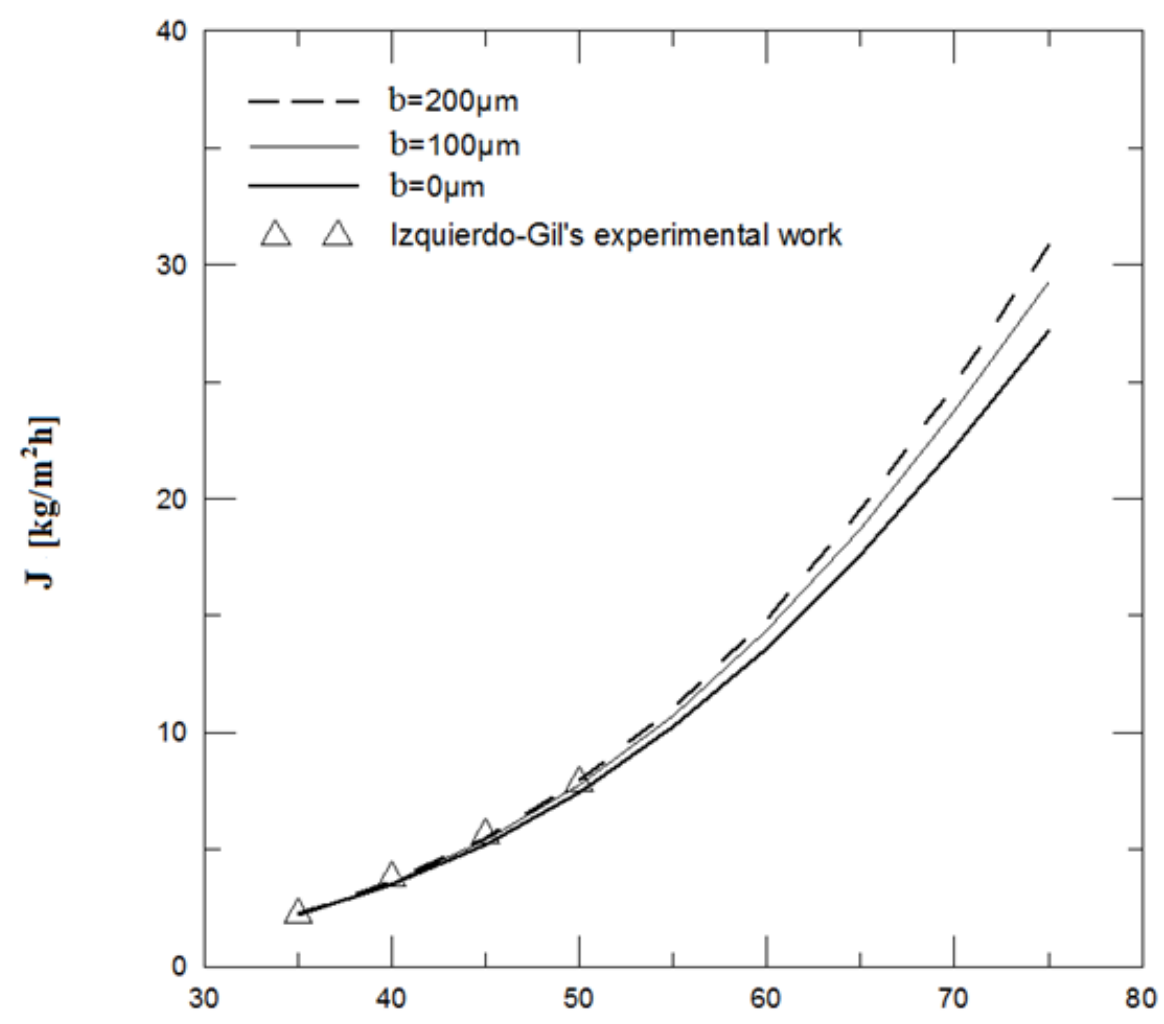

$\mathbf{T}_{\text {in }}\left[{ }^{\circ} \mathbf{C}\right]$

Figure 2: Effect of the inlet temperature on the permeate flux and comparison with the experiments of [33]

\section{Results and discussion}

For all calculations, the following general conditions were considered: $1=2 \mathrm{~mm}, \mathrm{~L}=20 \mathrm{~cm}, \mathrm{U}_{\mathrm{in}}=0.1 \mathrm{~m} / \mathrm{s}$, $\mathrm{C}_{\mathrm{in}}=0.025 ; \mathrm{T}_{\mathrm{C}}=25^{\circ} \mathrm{C}, \chi=1.5 ; \varepsilon=0.85 ; \mathrm{T}_{\mathrm{in}}=70^{\circ} \mathrm{C}, \delta_{\mathrm{m}}=0.3 \mathrm{~mm}, \delta_{\mathrm{g}}=2 \mathrm{~mm}, \delta_{\mathrm{c}}=1.5 \mathrm{~mm}, \mathrm{k}_{\mathrm{m}}=0.2 \mathrm{~W} / \mathrm{mK}$, $\mathrm{k}_{\mathrm{c}}=50 \mathrm{~W} / \mathrm{mK}$.

Results of this work were expressed in terms of profiles of temperature, axial velocity and concentration as well as distributions of several process parameters; these process parameters include the average permeate flux, the conductive heat flux, the total heat transfer and the process thermal efficiency. In order to show the impact of introducing a slip velocity boundary condition on process parameters, we have presented $J, \eta$ and $Q_{C}$ as a function of slip length (Table 2). The slip length $\mathrm{b}$ is varied from zero to $200 \mu \mathrm{m}$. For low values of $\mathrm{b}(0-1 \mu \mathrm{m})$, no significant effects on process parameters are noticed. While increasing b from 1 to $200 \mu \mathrm{m}$ induces a significant variation of the permeate flux, $J$.

Table 2: Slip length effects on process parameters 


\begin{tabular}{|c|c|c|c|c|c|c|}
\hline $\mathrm{b}[\mu \mathrm{m}]$ & 0 & 0.1 & 1 & 10 & 100 & 200 \\
\hline $\mathrm{J}\left[\mathrm{kg} / \mathrm{m}^{2} \mathrm{~h}\right]$ & 5.5736 & 5.5753 & 5.5893 & 5.7216 & 6.5757 & 7.0580 \\
\hline$\eta$ & 0.91630 & 0.91633 & 0.91650 & 0.91802 & 0.92643 & 0.93022 \\
\hline $\mathrm{Qc}\left[\mathrm{kJ} / \mathrm{m}^{2} \mathrm{~h}\right]$ & 1094.39 & 1094.43 & 1094.76 & 1097.96 & 1121.80 & 1138.50 \\
\hline
\end{tabular}

Fig. 3 shows the axial velocity, temperature and concentration profiles at the outlet of the channel as a function of $b$. In fact, axial velocity profiles are parabolic with a maximum velocity located at the center of the channel as it is the case for the Poiseuille flow for impermeable walls. One can see that when the slip flow condition is applied ( $b$ is non zero), the fluid particles adjacent to the solid surface of the membrane wall no longer attain the velocity of the solid surface. In the core region of the channel, the fluid decelerates and its maximum velocity occurring at the centerline of the membrane decreases significantly. So that, increasing $b$ leads to an increase of the fluid velocity at the membrane surface and a decrease of the centerline velocity. On the other side, slip impact on the temperature profile is significant. In fact, increasing $b$ leads to a reduction of the temperature drop which results in a higher temperature difference and the production of higher quantities of pure water. Moreover, the concentration increases significantly near the membrane wall due to vapor loss across the membrane. In the extended core region of the channel, the non-dimensional concentration is uniform and equal to one while in the thin layer in the vicinity of the wall, it increases from one to about 8 . It is of interest to indicate that increasing slip velocity induces a decrease of the solution concentration near the wall surface.

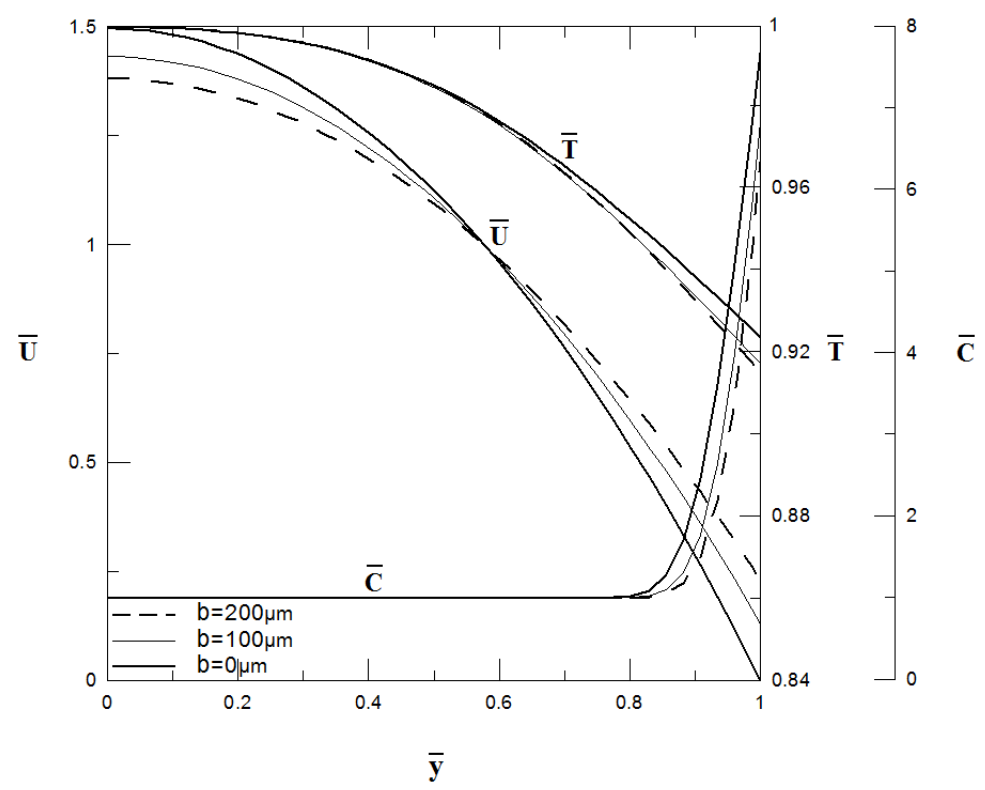

Figure 3: Velocity, temperature and concentration profiles at the outlet of the channel

Fig. 4 illustrates the variation of the permeate flux and the thermal efficiency as function of the inlet temperature for three values of the slip length, $b$. The presence of velocity slip increases the evaporation 
mass flux and the thermal efficiency. Besides, slip effects become more pronounced at higher inlet temperatures. In fact, for $\mathrm{T}_{\mathrm{in}}=80^{\circ} \mathrm{C}$, increasing $\mathrm{b}$ from zero to $200 \mu \mathrm{m}$ induces an increase of the permeate flux and the thermal efficiency by $33 \%$ and $1.7 \%$ respectively. The cooling temperature effect is depicted in Fig. 5. One can see that increasing $T_{c}$ leads to a decrease of the permeate flux and to a slight increase in the thermal efficiency. In fact, the cooling temperature has an important effect on the vapor flux because of the exponential increase of the partial pressure of the vapor (cold side) associated with the cooling temperature increase. Therefore, the driving force will be reduced inducing a significant decrease in the permeate flux. In the other hand, the slight increase of the efficiency is due to the fact that the rate of decrease of $\mathrm{Q}_{\mathrm{L}}$ (latent heat flux) is smaller than that of $\mathrm{Q}_{\mathrm{C}}$ (conduction heat flux).

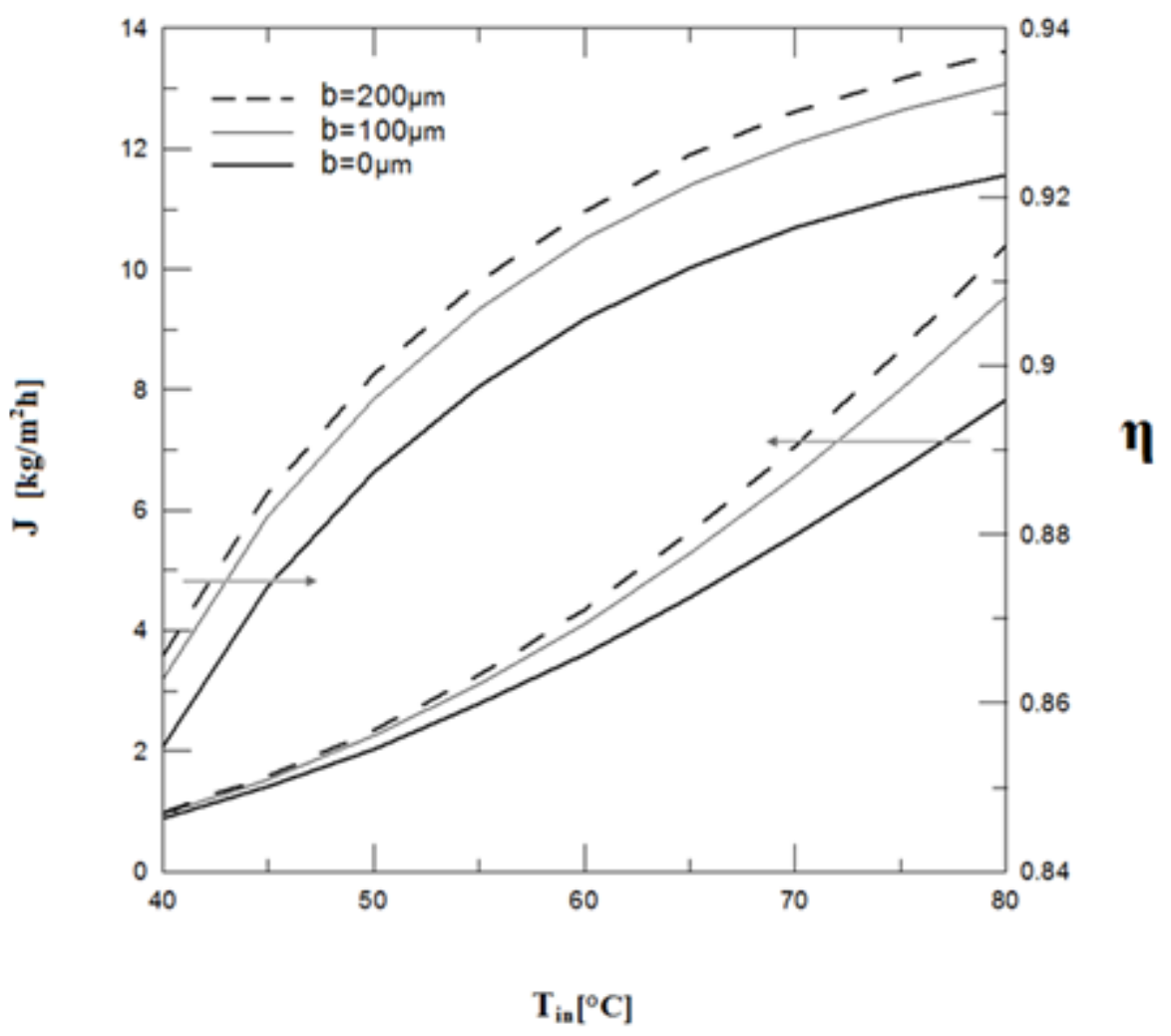

Figure 4: Variation of process parameters with inlet temperature 


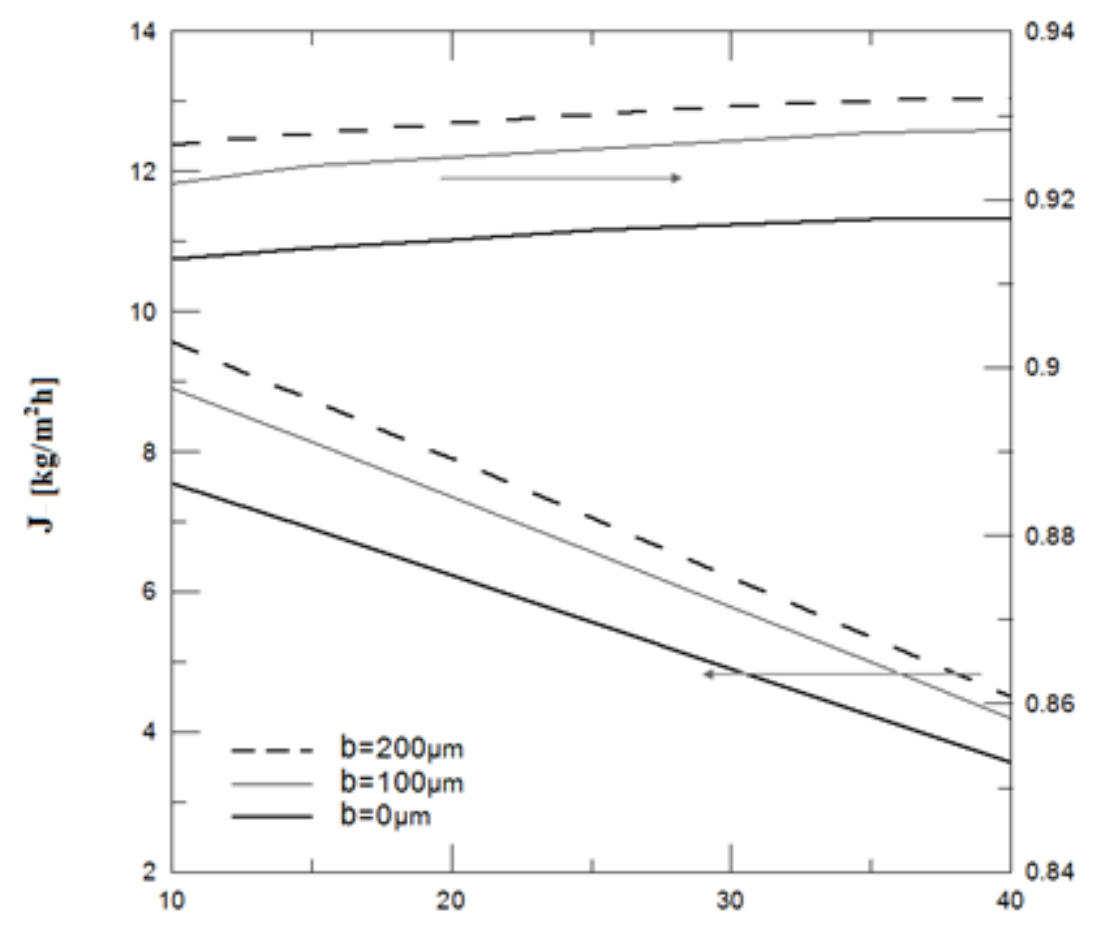

$\eta$

\section{$\left.\mathbf{T}_{\mathrm{C}}{ }^{\circ} \mathrm{C}\right]$}

Figure 5: Variation of the process parameters with the cooling temperature

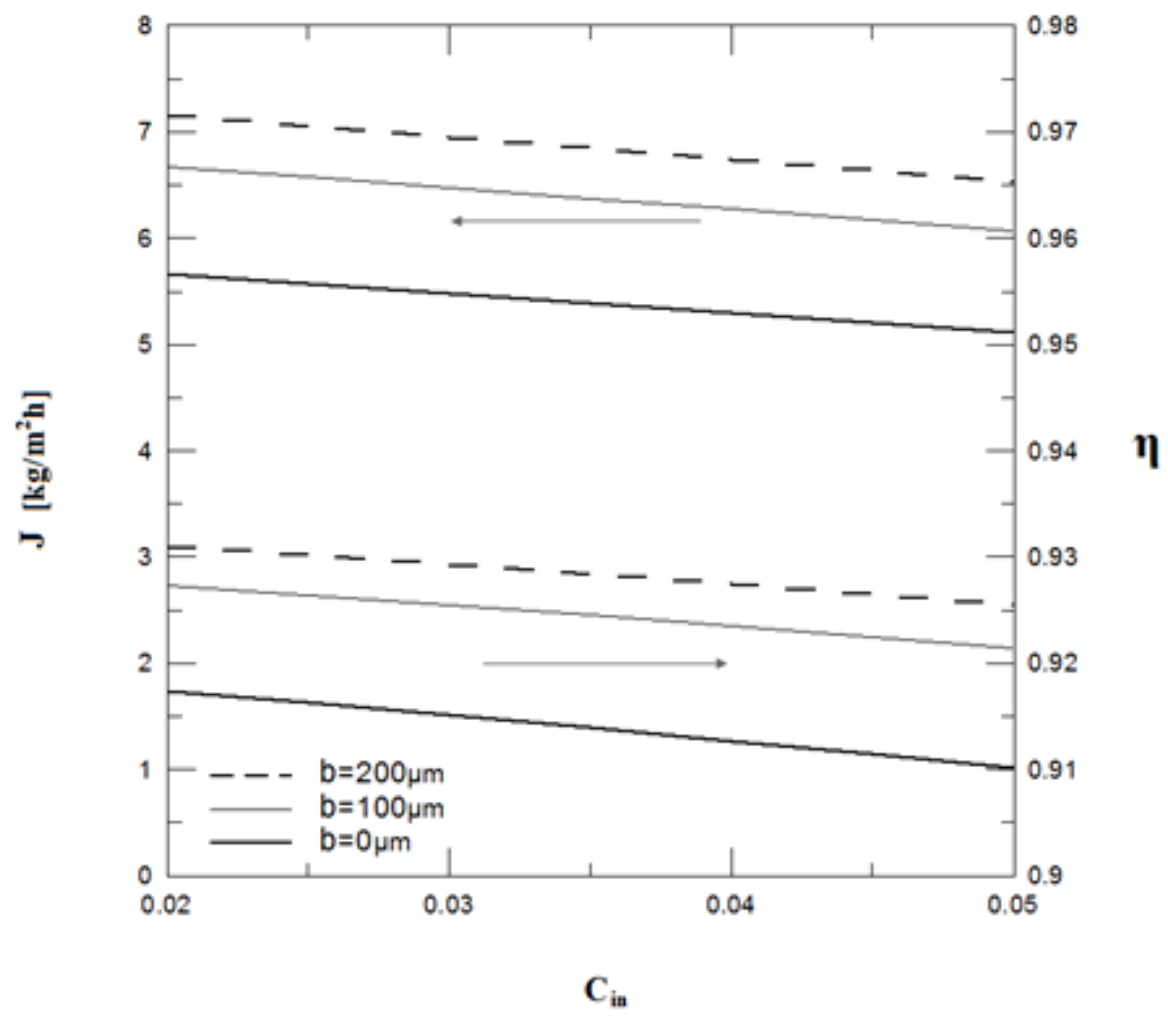

Figure 6: Evolution of $J$ and $\eta$ for different values of $C_{i n}$ and $b$

From Fig. 6, for all cases, varying $C_{i n}$ from 0.02 to 0.05 induces a small decrease of $J$ and $\eta$. The concentration of the inlet hot solution has a small effect on process parameters which represents an 
advantage of membrane distillation over pressure-driven membrane processes such as reverse osmosis. When slip occurs, $J$ and $\eta$ increase in comparison with the non-slip case.

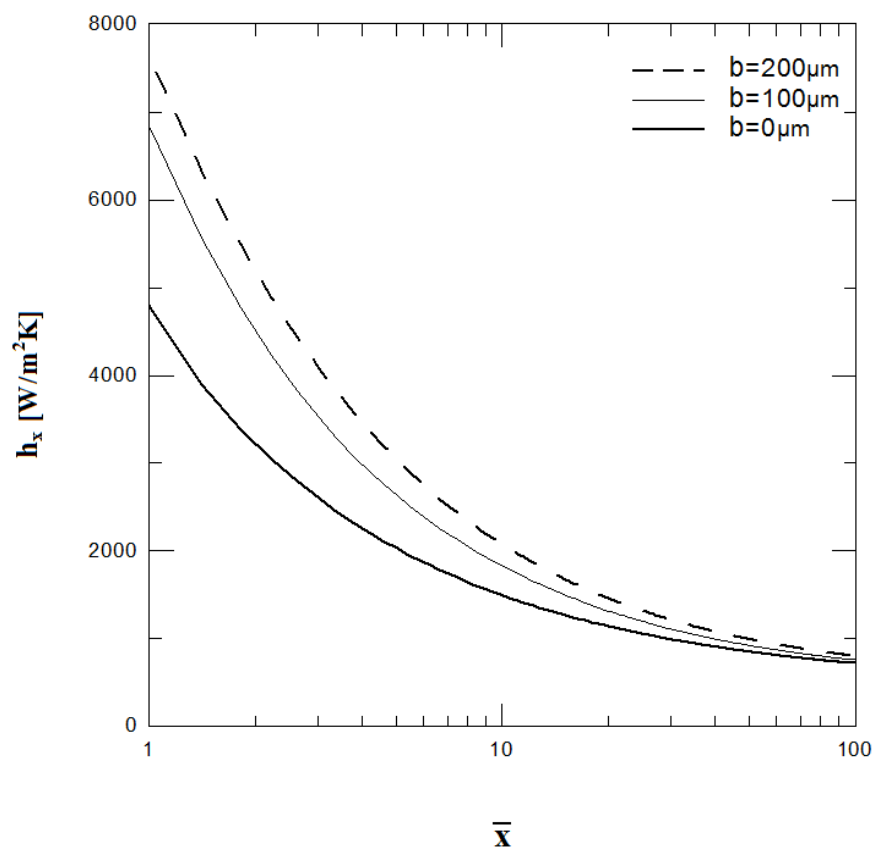

Figure 7: Variation of the local convective heat transfer coefficient

Fig. 7 presents another important quantity related to heat transfer mechanism. It shows the variation of the convective heat transfer along the channel. At the entrance of the duct, the velocity and temperature fields are under development. Therefore, the heat transfer coefficient is high and decreases as these fields approach the fully developed region. The values of $h_{x}$ are high due the latent heat transfer (evaporation process) at the hot membrane side. On the other hand, when the slip condition is introduced, $h_{x}$ increases especially at the inlet, but when reaching the outlet of the channel, this increase become small. Further work will include: (i) detailed modeling to represent transport phenomena within the membrane, (ii) predictive methods to relate slip length to membrane properties and choice of membrane material.

\section{Conclusion}

A numerical model solving the mass, momentum, energy and species conservation equations has been presented and discussed in this work for the case of feed water domain of a membrane distillation device. The air gap membrane distillation configuration was considered. The boundary conditions are adjusted to include the effect of slip flow on the performance of the distillation device. The results are expressed in terms of velocity, temperature and concentration profiles and of process parameters including the heat transfer coefficient and the process thermal efficiency for the case of continuum and slip flow models. It was found in particular that including the slip flow model gives a better representation of the process parameters. Increasing slip length from zero to $200 \mu \mathrm{m}$ was found to increase the permeate flux and the thermal efficiency by $33 \%$ and $1.7 \%$ respectively. 


\section{Acknowledgment}

The first author (Dr J. Orfi) extends his appreciation to the Deanship of scientific research at King Saud University (Research group project No: RGP-VPP-091).

\section{References}

[1] M. Rommel, J. Koschikowski, and M. Wighaus, 2007, "Solar Driven Desalination systems basedon MembraneDesalination" in Solar Desalination for the $21^{\text {st }}$ Century, Editors Rizzuti et al., pp. 247257.

[2] M.S. El-Bourawi, Z. Ding, R. Ma, and M.A. Khayat, 2006, "Framework for better understanding membrane distillationseparation process' Journal of Membrane Science, 285, pp. 4-29.

[3] L. M. Camacho, L. Dumée, J. Zhang, J. Li, M. Duke, J. Gomez and S. Gray, 2013, "Advances in Membrane Distillation for Water Desalination and Purification Applications", Water,5, pp. 94-196.

[4] G. Ramon, Y. Agnon and C. Dosretz, 2009, "Heat transfer in vacuum membrane distillation: Effect of velocity slip", Journal of Membrane Science, 331(1-2), pp. 117-125.

[5] Pratanu Roy, N.K.Anand and D. Banerjee, 2013, "Liquid slip and heat transfer in rotating rectangular microchannels", International Journal of Heat and Mass Transfer, 62, pp. 184-199.

[6] S.V. Garimella and C.B. Sobhan,2003, "Transport in microchannels - a critical review", Annu. Rev. Heat Transfer13, pp. 1-50.

[7] C. Cottin-Bizonne, S. Jurine, J. Baudry, J. Crassous, F. Restagno and E. Charlaix, 2002, "Nanorheology: an investigation of the boundary condition at hydrophobic and hydrophilic interfaces", Eur. Phys. J. E: Soft Matter Biol. Phys.9, pp. 47-53.

[8] E. Bonaccurso, M. Kappl and H.J. Butt, 2002, "Hydrodynamic force measurements: boundary slip of water on hydrophilic surfaces and electrokinetic effects", Phys. Rev. Lett.88, 76103.

[9] D. C. Tretheway and C. D. Meinhart, 2004, "A generating mechanism for apparent fluid slip in hydrophobic microchannels", Physics of fluids, 16, pp. 1509-1515.

[10] D. C. Tretheway and C. D. Meinhart, "Apparent fluid slip at hydrophobic microchannel walls," Phys. Fluids 14, L9 2002!.

[11] R. Pit, H. Hervet and L. Leger, 2000, "Direct experimental evidence of slip in hexadecane: solid interfaces", Phys. Rev. Lett.85, pp. 980-983.

[12] C. Cottin-Bizonne, B. Cross, A. Steinberger, and E. Charlaix, 2005, "Boundary slip on smooth hydrophobic surfaces: intrinsic effects and possible artifacts ", Phys. Rev. Lett.94:056102.

[13] C.H. Choi and C.J. Kim, 2006, "Large slip of aqueous liquid flow over a nanoengineered superhydrophobic surface", Phys. Rev. Lett. 9666001.

[14] Lee C, Choi C-H, Kim C-J. 2008. Structured surfaces for giant liquid slip. Phys. Rev. Lett. 101:064501

[15] J. Ou and J.P. Rothstein, 2005, "Direct velocity measurements of the flow past drag-reducing ultrahydrophobic surfaces" Phys. Fluids 17103606.

[16] Joseph P, Tabeling P. 2005. Direct measurement of the apparent slip length. Phys. Rev. E 71:035303

[17] Pit R, Hervet H, Leger L. 1999. Friction and slip of a simple liquid at a solid surface. Tribol. Lett. 7:147-52

[18] Jin S, Huang P, Park J, Yoo JY, Breuer KS. 2004. Near-surface velocity using evanescent wave illumination.Exp. Fluids 37:825-33

[19] Choi C-H, Johan K, Westin A, Breuer KS. 2003. Apparent slip flows in hydrophilic and hydrophobic microchannels. Phys. Fluids 15:2897-902

[20] Schnell E. 1956. Slippage of water over nonwettable surfaces. J. Appl. Phys. 27:1149-52

[21] Baudry J, Charlaix E, Tonck A, Mazuyer D. 2001. Experimental evidence for a large slip effect at a nonwetting fluid-surface interface. Langmuir 17:5232-36 
[22] N.J. Shirtcliffe, G. McHale, S. Atherton, M.I. Newton, An introduction to superhydrophobicity, Adv. Colloid Interface Sci. 161 (2010) 124-138.

[23] X. Zhang, F. Shi, J. Niu, Y. Jiang, Z. Wang, Superhydrophobic surfaces: from structural control to functional application, J. Mater. Chem. 18 (2008) 621-633.

[24] Amir Razmjou,Ellen Arifin, Guangxi Dong, Jaleh Mansouri, Vicki Chen,"Superhydrophobic modification of $\mathrm{TiO}_{2}$ nanocomposite PVDF membranes for applications in membrane distillation", Journal of Membrane Science, 415-416, 850-863.

[25] R. Singh and R.L. Laurence,1979a, "Influence of slip velocity at a membrane surface on ultrafiltartion performance-I- Tube flow system", International Journal of Heat and Mass Transfer 12 pp. 731-737.

[26] R. Singh and R. L. Laurence, 1979b, "Influence of slip velocity at a membrane surface on ultrafiltration performance-II- Channel flow system", International Journal of Heat and Mass Transfer 22 pp. 721-729.

[27] V.M. Soundalgekar and V.G. Divekar, 1973, "Laminar slip flow through a uniform circular pipe with small suction", Publications de l'Institut de Mathematique,16 pp. 147-157.

[28] J. Orfi and N. Loussif, 2010, "Modeling of a Membrane Distillation unit for Desalination", Book Chapter, in Desalination: Methods Costs and Technology. Editor: I. A. Urboniene, pp. 143-174; Nova Science Publishers, NY.

[29] A. Oron, S.H. Davis, S.G. Bankoff, Long scale evolution of thin liquid films, Rev.Mod. Phys. 69 (1997) 931-980.

[30] A. Bejan, 2004, Convective Heat Transfer, Third Edition, Wiley, p. 694.

[31] A.M. Alklaibi,and N. Lior, 2005,"Transport analysis of air gap membrane distillation", Journal of Membrane Science, 255 pp.239-253.

[32] H. K. Versteeg and W. Malalasekera, 2007, An Introduction to Computational Fluid Dynamics: The Finite Volume Method, Pearson and Prentice Hall, 2nd edition, London.

[33] M.A. Izquierdo-Gil, M.C. Garcõ̂̂A-Payo and C. FernaÂndez-Pineda, 1999, "Air gap membrane distillation of sucrose aqueous solutions", Journal of Membrane Science,155 pp. 291-307. 